\title{
A New Calculation Method of Dynamic Kill Fluid Density Variation during Deep Water Drilling
}

\author{
Honghai Fan, ${ }^{1}$ Song Deng, ${ }^{1}$ Weiyan Ren, ${ }^{1}$ Xili Duan, ${ }^{2}$ Cong Cui, ${ }^{2}$ and Jing Yang ${ }^{1}$ \\ ${ }^{1}$ State Key Laboratory of Petroleum Resources and Engineering, China University of Petroleum, Beijing 102249, China \\ ${ }^{2}$ Faculty of Engineering \& Applied Science, Memorial University, St. John's, NL, Canada A1B 3X5 \\ Correspondence should be addressed to Song Deng; 13699286998@126.com
}

Received 26 September 2016; Accepted 19 February 2017; Published 2 March 2017

Academic Editor: Sergii V. Kavun

Copyright (c) 2017 Honghai Fan et al. This is an open access article distributed under the Creative Commons Attribution License, which permits unrestricted use, distribution, and reproduction in any medium, provided the original work is properly cited.

\begin{abstract}
There are plenty of uncertainties and enormous challenges in deep water drilling due to complicated shallow flow and deep strata of high temperature and pressure. This paper investigates density of dynamic kill fluid and optimum density during the kill operation process in which dynamic kill process can be divided into two stages, that is, dynamic stable stage and static stable stage. The dynamic kill fluid consists of a single liquid phase and different solid phases. In addition, liquid phase is a mixture of water and oil. Therefore, a new method in calculating the temperature and pressure field of deep water wellbore is proposed. The paper calculates the changing trend of kill fluid density under different temperature and pressure by means of superposition method, nonlinear regression, and segment processing technique. By employing the improved model of kill fluid density, deep water kill operation in a well is investigated. By comparison, the calculated density results are in line with the field data. The model proposed in this paper proves to be satisfactory in optimizing dynamic kill operations to ensure the safety in deep water.
\end{abstract}

\section{Introduction}

Dynamic kill is one of the most efficient ways to deal with the low fracture pressure of shallow in seabed. By adopting this method, well liquid with initial pressure is pumped into the well at first, making the bottom-hole pressure equal or exceed the formation pore pressure to prevent further invasion of the borehole formation fluid. Then a heavier pressure well liquid is gradually added in order to complete kill and reach the static stable state. Unlike the conventional kill methods by means of wellhead to generate back-pressure to balance the underlying pressure, dynamic kill allows us to balance the formation pore pressure with the help of bottom-hole pressure by overcoming the annulus flow resistance.

Several well control methods have been established so far. A mathematical model for well flow control was developed. Although this model is simple, it is inconsistent with the actual situation as it ignored the frictional loss of annulus fluid [1]. Based on the Nickens theory, a model of deep water well control was put forward, which has been used widely in deep water well control in previous studies; however, dynamic kill was not proposed in this model [2]. The iterative method was proposed, which comprehensively considered the factors such as shape of borehole, gas invasion, and the kill process [3]. Li et al. studied two-phase flow in the well and solved the partial differential equations of the flows [4]. Later, Sun et al. proposed a multiphase flow calculation method on the basis of the well control by dynamic kill in deep water [5].

In the previous models, some relatively simple factors such as friction in the choke line were considered. However, a comprehensive analysis of various fluid components in the wellbore would be required in actual applications. Despite the comprehensiveness of the multiphase flow model, it is not applicable to engineering applications due to a lack of details in calculation of well control parameters and complexity of seven components. Therefore, a practical and simple calculation method is needed. A better model for calculation of well kill fluid density is proposed in which water phase, oil phase, gas phase, and solid phase are thought out.

One key parameter of dynamic kill is the volume of a well. Calculation of volume requires accurate prediction of the well fluid density. Therefore, research on well fluid density variation plays an important role in dynamic kill analysis and operation: conventional methods for kill fluid density 
prediction have been widely used in petroleum drilling site shown below $[6,7]$ :

$$
\rho=\frac{102\left[p_{p}+p_{e}-G_{p}(H-h)\right]}{h},
$$

calculation method of additional stress:

$$
\rho=\frac{102\left(p_{p}+p_{e}\right)}{h},
$$

calculation method of pressure ratio:

$$
\rho=\frac{102 K p_{p}}{h},
$$

calculation method of additional equivalent density:

$$
\rho=\rho_{\mathrm{md}}+\frac{P_{e}}{h}
$$

Among them, $p_{e}$ is additional pressure, $\mathrm{MPa} ; p_{p}$ is pore pressure, $\mathrm{MPa} ; \rho_{\mathrm{md}}$ is formation fluid pressure, $\mathrm{g} / \mathrm{cm}^{3} ; h$ is depth of kill well, $\mathrm{m} ; H$ is half depth of oil layer, $\mathrm{m} ; G_{p}$ is gradient of pore pressure, $\mathrm{MPa} / \mathrm{m}$;

Although the method is convenient, it has the following disadvantages for it does not resolve the problems in kill fluid such as structure and well depth, especially the difference between deep dynamic kill process, geological conditions, engineering, and onshore drilling. These methods are used to monitor the formation pressure so as to determine drilling fluid pressure determination, while they are not applicable in engineering simply because it is rather difficult to measure the formation pressure of gas invasion or blowout in the drilling process.

The principle of $U$ type tube was used for well kill fluid density calculation whereas the effect of fluid temperature pressure into account was not taken into account in this method [8]. The effects of low temperature on rheological parameters of drilling fluid and the annulus circulating pressure loss of each well section are considered to calculate the density of dynamic kill drilling fluid density; however, the multiple phases and components in dynamic kill in deep water were not taken into account [9]. The gas migration rule of gas-liquid two-phase flow is adopted to obtain the pressure determination on shallow well liquid security value while the effect of temperature is not considered [10]. Based on the theory of gas-liquid two-phase flow pressure and pressure characteristics of whole wellbore derived from Y type tube, calculation on fluid density of well section was derived and design method of kill fluid density was introduced without any consideration for influence of temperature and pressure [11]. A new method to calculate the density of dynamic kill well is also proposed which gets the inlet kill well fluid instantaneous density of mixing slurry according to the instantaneous displacement of seawater and drilling fluid weighting at a certain time and then obtains density value of each point in the borehole by the principle of integration. Despite instantaneous density and improvement in calculation accuracy of density that could be obtained by this method, the changes of temperature and pressure in deep water are not thought about, which may have significant effects on kill fluid density [12]. Improvement is therefore desired from further research.

At present, same method has been adopted for calculation of deep water well kill fluid density in on-land drilling. However, deep water well kill is faced with the problem of narrow fluid density window and difficulty in determination of fracture pressure. Density change in process of deep water drilling is not taken into account in current calculation method [13]. The existing determination of well kill method mainly adopts initial seawater density, neglecting the fluid density variation in complicated environment. With variability in high temperature of deep water and the high temperature and pressure of deep oil and gas reservoir, it is crucial to predict the fluid density variation with change of temperature and pressure which is significant to deep water drilling development and avoid deep water drilling accident and ensure safety. Therefore, a multiphase multicomponent dynamic kill well fluid density model under the temperature and pressure variations in deep water is proposed in this paper.

\section{Calculation Model}

\subsection{Wellbore Temperature and Pressure Field in Dynamic Kill}

2.1.1. Seawater and Formation Temperature Field Model. Regression of seawater temperatures is given [14]:

$$
T=a_{1}+\frac{a_{2}}{1+e^{\left(a_{0}+h\right) / a_{3}}}, \quad(h \geq 200 \mathrm{~m}),
$$

where $a_{0}, a_{1}, a_{2}$, and $a_{3}$ are correlation coefficients, $a_{0}=130.1$, $a_{1}=39.4, a_{2}=37.1$, and $a_{3}=402.7$; $T$ is sea water temperature, ${ }^{\circ} \mathrm{C}$; $h$ is sea water depth, $\mathrm{m}$.

Formation temperature is given [15]:

$$
T_{e i}=T_{s}+G z \text {, }
$$

where $T_{s}$ is a representative temperature, ${ }^{\circ} \mathrm{C}$; $G$ represents geothermal gradient, ${ }^{\circ} \mathrm{C} / \mathrm{m}$.

2.1.2. Wellbore Temperature Field Model in Dynamic Kill. The equation for temperature field in drill string is [16]

$$
\frac{\mathrm{d} T_{p}}{\mathrm{~d} z}=\frac{T_{a}-T_{p}}{B}+T_{f p},
$$

where $T_{f p}$ is a temperature caused by pressure loss in drill string, ${ }^{\circ} \mathrm{C} ; T_{f p}=\left(1 / \rho_{m} C_{m}\right)\left(\mathrm{d} P_{f p} / \mathrm{d} z\right) ; B=\dot{m} C_{p m} / 2 \pi R_{p} U_{p}$; $C_{p m}$ is drill fluid or kill fluid specific heat capacity, $\mathrm{J} /\left(\mathrm{kg} \cdot{ }^{\circ} \mathrm{C}\right)$; $R_{p}$ is drill string outside radius, $\mathrm{m} ; U_{p}$ is heat transfer coefficient from annulus to drill string, $\mathrm{J} /\left(\mathrm{m}^{2} \cdot \mathrm{s} \cdot \mathrm{K}\right) ; T_{a}$ is the temperature in annulus; $T_{p}$ is the Internal temperature of drill string.

Annulus temperature field is

$$
\frac{\mathrm{d} T_{a}}{\mathrm{~d} z}=\frac{1}{B}\left(T_{a}-T_{p}\right)-\frac{1}{A}\left(T_{e i}-T_{a}\right)-T_{f a} .
$$


In this equation, temperature caused by fluid pressure loss is calculated by the equation $T_{f a}=\left(1 / \rho_{m} C_{m}\right)\left(\mathrm{d} P_{f a} / \mathrm{d} z\right) ; A=$ $\dot{m} C_{p m}\left(K_{f}+R_{w} U_{a} T_{D}\right) / 2 \pi R_{w} U_{a} K_{f}, T_{e i}$ is well wall temperature, ${ }^{\circ} \mathrm{C} ; K_{f}$ is formation layer thermal conductivity, $\mathrm{J} /\left(\mathrm{m}^{2} \cdot \mathrm{s} \cdot{ }^{\circ} \mathrm{C}\right) ; R_{w}$ is well radius, $\mathrm{m} ; U_{a}$ is heat transfer coefficient between hohlraum drill fluid and well wall in the well string, $\mathrm{J} /\left(\mathrm{m}^{2} \cdot \mathrm{s} \cdot \mathrm{K}\right)$.

2.1.3. Wellbore Pressure Field in Dynamic Kill. Bottom-hole pressure can be represented by the following equations:

$$
\begin{aligned}
p_{\mathrm{bhc}} & =p_{\mathrm{hy}}+p_{a}+p_{\mathrm{wh}}, \\
p_{\mathrm{hy}} & =\int_{H_{0}}^{H} \rho g \mathrm{~d} H, \\
p_{a} & =p_{\mathrm{al}}+p_{\mathrm{at}},
\end{aligned}
$$

where $p_{\text {bhc }}$ is bottom-hole circulating pressure; $p_{\text {hy }}$ is hydrostatic fluid column pressure; $p_{a}$ is annular pressure loss; $p_{\mathrm{wh}}$ is surface casing pressure; $p_{\mathrm{al}}$ is total pressure loss of power law fluid in annulus laminar flow section; $p_{\text {at }}$ is total pressure loss of power law fluid in annulus turbulent flow section.

Assume that laminar flow sections in drill string are $N_{1}$, turbulent flow sections are $N_{2}$, and $M_{1}$ laminar flow sections in the annulus with the length of each section are $L_{i}$; sectional area is $A_{i}$, annulus external diameter and inner diameter of each section are, respectively, $D_{o i}$ and $D_{i i}$ :

$$
\begin{aligned}
p_{\mathrm{al}}= & B_{0} Q^{n} \sum_{i=1}^{M_{1}} \frac{L_{i}}{D_{\mathrm{hyi}}^{n+1} A_{i}^{n}} \\
& +D_{b}^{2} R\left(\rho_{s}-\rho\right) g \sum_{i=1}^{M_{1}} \frac{A_{i} L_{i}}{\left(D_{o i}^{2}-D_{i i}^{2}\right)\left(Q-K^{\prime} v_{s} A_{i}\right)}, \\
p_{\text {at }}= & k_{1} Q^{k_{2}} \sum_{j=1}^{M_{2}} \frac{L_{j}}{D_{\mathrm{hyj}}^{n b+1} A_{j}^{k_{2}}} \\
& +D_{b}^{2} R\left(\rho_{s}-\rho\right) g \sum_{j=1}^{M_{2}} \frac{A_{j} L_{j}}{\left(D_{o j}^{2}-D_{i j}^{2}\right)\left(Q-v_{s} A_{j}\right)} .
\end{aligned}
$$

Pressure distribution in well bore is therefore

$$
\begin{aligned}
p_{\mathrm{bhc}}= & p_{\mathrm{wh}}+\int_{H_{0}}^{H} \rho g \mathrm{~d} H+B_{0} Q^{n} \sum_{i=1}^{M_{1}} \frac{L_{i}}{D_{\mathrm{hyi}}^{n+1} A_{i}^{n}} \\
& +D_{b}^{2} R\left(\rho_{s}-\rho\right) g \sum_{i=1}^{M_{1}} \frac{A_{i} L_{i}}{\left(D_{o i}^{2}-D_{i i}^{2}\right)\left(Q-K^{\prime} v_{s} A_{i}\right)} \\
& +k_{1} Q^{k_{2}} \sum_{j=1}^{M_{2}} \frac{L_{j}}{D_{\text {hyj }}^{n b+1} A_{j}^{k_{2}}} \\
& +D_{b}^{2} R\left(\rho_{s}-\rho\right) g \sum_{j=1}^{M_{2}} \frac{A_{j} L_{j}}{\left(D_{o j}^{2}-D_{i j}^{2}\right)\left(Q-v_{s} A_{j}\right)},
\end{aligned}
$$

where $A$ is annulus cross-sectional area, $\mathrm{m}^{2} ; L$ is length when calculating annulus pressure loss for different sections, $\mathrm{m}$;
$D_{b}$ is drill bit diameter, $\mathrm{m} ; R$ is rate of penetration, $\mathrm{m} / \mathrm{s}$; $v_{s}$ is chip slip velocity, $\mathrm{m} / \mathrm{s} ; v_{f}$ is upward velocity of fluid in annulus, $\mathrm{m} / \mathrm{s} ; K^{\prime}$ is velocity correction factor; $D_{o}$ is well diameter, $\mathrm{m} ; D_{i}$ is drill string external diameter; $D_{\text {hy }}$ is annulus hydraulic diameter, $\mathrm{m} ; p_{\mathrm{pt}}$ is total pressure loss of power law turbulent fluid in the circular pipe; $B_{0}=4 K[4(2 n+$ $1) / n]^{n}$.

\subsection{Kill Fluid Density Model}

2.2.1. Density Component Model. Kill fluid density is calculated based on the composite model [17]:

$$
\rho(p, T)=\frac{\rho_{o} f_{o}+\rho_{w} f_{w}+\rho_{s} f_{s}+\rho_{c} f_{c}}{1+f_{o}\left(\rho_{o} / \rho_{\mathrm{oi}}-1\right)+f_{w}\left(\rho_{w} / \rho_{\mathrm{wi}}-1\right)},
$$

where $\rho_{o}$ is oil density of kill fluid, $\mathrm{kg} / \mathrm{m}^{3} ; \rho_{w}$ is water density of kill fluid, $\mathrm{kg} / \mathrm{m}^{3} ; \rho_{s}$ is solid phase density of kill fluid, $\mathrm{kg} / \mathrm{m}^{3} ; \rho_{c}$ is chemical additive density, $\mathrm{kg} / \mathrm{m}^{3} ; f_{o}$ is the volume fraction of oil phase; $f_{w}$ is the volume fraction of water phase; $f_{s}$ is the volume fraction of solid phase; $f_{c}$ is the volume fraction of chemical additive; $\rho_{\mathrm{oi}}$ is the oil phase density after volume changes caused by temperature and pressure, $\mathrm{kg} / \mathrm{m}^{3}$; $\rho_{\mathrm{wi}}$ is the water phase density after volume changes caused by temperature and pressure, $\mathrm{kg} / \mathrm{m}^{3}$.

Consider the kill fluid as solid and liquid phase in which the liquid phase is water or oil and the solid phase are all other liquid immiscible materials, except cuttings.

The solid phase is assumed to have $N$ materials, the volume ratios are $k_{1}, k_{2}, \ldots, k_{N}$, and the liquid phase volume ratio is $\lambda$ among them. So

$$
\lambda+\sum_{i=1}^{N} k_{i}=1
$$

The following equation is established by (10) and (11):

$$
\rho(p, T)=\frac{\rho_{0}\left(p_{0}, T_{0}\right)}{1+\lambda\left(\rho_{f}\left(p_{0}, T_{0}\right) / \rho_{f}(p, T)-1\right)},
$$

where $\rho_{f}\left(p_{0}, T_{0}\right)$ is the density of kill liquid phase under atmospheric temperature and pressure, $\mathrm{kg} / \mathrm{m}^{3} ; \rho_{f}(p, T)$ is the density under certain temperature and pressure $(p, T)$, $\mathrm{kg} / \mathrm{m}^{3}$.

In (16) it is notable that the key to calculate kill fluid density under a certain temperature and pressure is to know the liquid density variation with temperature and pressure.

Density of the fluid solid phase is not affected by the temperature and pressure in the kill process. The liquid phase is obviously influenced by temperature and pressure. The effect of temperature is thermal expansion, and pressure affects the compression. As a result, the underground density is no longer equal to surface density because of the above factors.

2.2.2. Liquid Water Density. Under a given temperature, liquid water density at different pressures can be expressed as

$$
\rho_{w}=\rho_{w 0} e^{\alpha\left(p-p_{0}\right)},
$$


TABLE 1: Water compression coefficient under normal temperature and different pressures.

\begin{tabular}{lccccc}
\hline$T\left({ }^{\circ} \mathrm{C}\right)$ & \multicolumn{5}{c}{$p(\mathrm{~atm})$} \\
& 5 & 10 & 20 & 40 & 80 \\
\hline 20 & 0.000052 & 0.000052 & 0.000052 & 0.000051 & 0.000050 \\
\hline
\end{tabular}

TABLE 2: The coefficient of expansion of water under different temperatures and pressure.

\begin{tabular}{lccccc}
\hline$p(\mathrm{~atm})$ & $0 \sim 10$ & $10 \sim 20$ & $40 \sim 50$ & $60 \sim 70$ & $90 \sim 100$ \\
\hline 1 & 0.0000 & 0.00015 & 0.00042 & 0.00055 & 0.00071 \\
100 & 0.0000 & 0.00016 & 0.00042 & 0.00054 & 0.00070 \\
200 & 0.0000 & 0.00018 & 0.00042 & 0.00053 & 0.00070 \\
500 & 0.0001 & 0.00023 & 0.00042 & 0.00052 & 0.00066 \\
\hline
\end{tabular}

where $\alpha$ is compression coefficient, $\mathrm{Pa}^{-1} ; \rho_{w 0}$ is water density at initial state, $\mathrm{kg} / \mathrm{m}^{3} ; p_{0}$ is the initial pressure, $1 \mathrm{~atm}$.

Similarly under a given pressure, water density at different temperatures is expressed as

$$
\rho_{w}=\rho_{w 0} e^{\beta\left(T_{0}-T\right)},
$$

where $\beta$ is expansion coefficient, ${ }^{\circ} \mathrm{C}^{-1} ; T_{0}$ is initial temperature.

For different temperatures and pressures, liquid water density can be calculated using (17) and (18). The specific calculation process is shown in Table 1.

The compression coefficient can be obtained by carrying on data fitting to compression coefficient under normal water temperature $\left(20^{\circ} \mathrm{C}\right)$ and different pressure:

$$
\alpha=-9 \times 10^{-7} \ln p+5 \times 10^{-5} .
$$

With a superposition method, at $20^{\circ} \mathrm{C}, \mathrm{N}$ atmospheric pressure, the expression for the calculation of water density is

$$
\rho_{w(N, 20)}=998.2 e^{(N-1)\left(-9 \times 10^{-7} \ln p+5 \times 10^{-5}\right)},
$$

where $\rho_{w(N, 20)}$ is water density at $20^{\circ} \mathrm{C} ; N$ is atmospheric (at), $\mathrm{kg} / \mathrm{m}^{3}$.

Similarly, under a given pressure, water density at different temperatures can be obtained by using data fitting of the expansion coefficient from Table 2. The fitting equation can be obtained:

$$
\begin{aligned}
& p=1 \mathrm{~atm}: \beta=-4 \times 10^{-8} T^{2}+1 \times 10^{-5} T-10^{-4}\left(R^{2}=\right. \\
& 0.9989) . \\
& p=100 \mathrm{~atm}: \beta=-4 \times 10^{-8} T^{2}+1 \times 10^{-5} \mathrm{~T}-6 \times 10^{-5} \\
& \left(R^{2}=0.9992\right) . \\
& p=200 \mathrm{~atm}: \beta=-3 \times 10^{-8} T^{2}+1 \times 10^{-5} \mathrm{~T}-2 \times 10^{-5} \\
& \left(R^{2}=0.9987\right) . \\
& p=500 \mathrm{~atm}: \beta=-2 \times 10^{-8} T^{2}+8 \times 10^{-6} \mathrm{~T}-8 \times 10^{-5} \\
& \left(R^{2}=0.9989\right) .
\end{aligned}
$$

Using a superposition method, at the initial pressure of one pressure (1 atm), water density can be calculated:

$$
\rho_{w(1, N)}=998.2 e^{(20-N) f\left(\beta_{N}\right)} .
$$

$\rho_{w(1, N)}$ is the density of water when initial pressure is $1 \mathrm{~atm}$ and initial temperature is $N^{\circ} \mathrm{C}, \mathrm{kg} / \mathrm{m}^{3} ; f\left(\beta_{N}\right)$ is coefficient of expansion of water when pressure is $1 \mathrm{~atm}$; and temperature is $N^{\circ} \mathrm{C}, 1 /{ }^{\circ} \mathrm{C}$.

According to (20) and (21), water density is calculated which is shown in Figure 1. In this figure, actual operation situation is considered with the temperatures ranging from $20^{\circ} \mathrm{C}$ to $200^{\circ} \mathrm{C}$ and the pressures from $10 \mathrm{~atm}$ to $1200 \mathrm{~atm}$.

In order to improve the precision of calculation, the density of water can be drawn by using the nonlinear regression method above. Under a given pressure, the relationship between water density and temperature can be presented by

$$
\rho_{w}=a T^{2}+b T+c .
$$

Coefficients $a$ and $b$ are constants of water characteristics, which can be calculated by means of nonlinear regression. For further detailed characterizations of the density changes of liquid water, a segmentation method can be used, with steps of $10 \mathrm{~atm}$; then (22) can be changed to

$$
\rho_{w i}=a_{i} T^{2}+b_{i} T+c_{i}, \quad\left(p_{i-10} \leq p \leq p_{i}\right) .
$$

By fitting the data in Figure 1, water density at different pressure and temperatures can be calculated with

$$
\rho_{w}(p, T)= \begin{cases}-0.0133 T^{2}+23.97 T-10670 ; & \left(1 \leq p \leq 10 ; R^{2}=0.9940\right) \\ \vdots \\ -0.0018 T^{2}-0.2635 T+1041.6 ; & \left(880 \leq p \leq 890 ; R^{2}=0.9999\right) \\ \vdots & \\ -0.0014 T^{2}-0.3256 T+1051.9 ; & \left(1150 \leq p \leq 1160 ; R^{2}=0.9995\right) .\end{cases}
$$




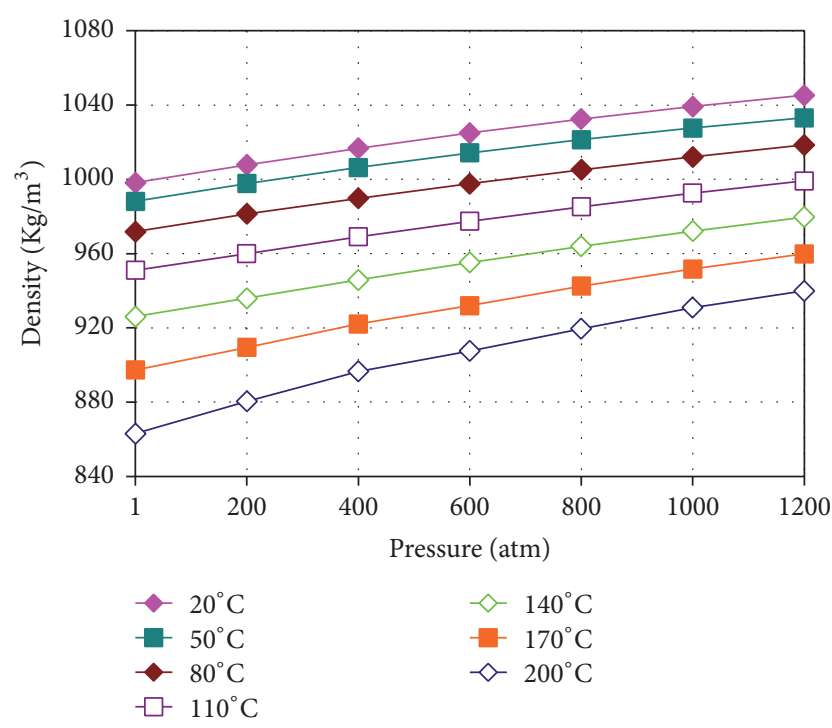

FIGURE 1: Density of water under different temperatures and pressures.

2.2.3. Oil Phase Density. The oil phase density also changes along with temperature and pressure. The empirical correlation is expressed as $[18,19]$

$$
\rho_{o(p, T)}=A_{0}+A_{1} p T+A_{2} p+A_{3} p^{2}+A_{4} T+A_{5} T^{2}
$$

where $\rho_{o(p, T)}$ is the liquid oil density under a given temperature and pressure, $\mathrm{kg} / \mathrm{m}^{3}, A_{0}, A_{1}, A_{2}, A_{3}, A_{4}$, and $A_{5}$ are constants, $A_{0}=880.7, A_{1}=3.97737 \times 10^{-10}, A_{2}=1.8574 \times$ $10^{-7}, A_{3}=2.2548 \times 10^{-15}, A_{4}=-0.648$, and $A_{5}=-1.6741 \times$ $10^{-4}$.

This correlation has a pretty good precision. The following modified correlation is proposed by comprehensively considering oil phase density in different borehole sizes; then method of concentrated summation of sections is adopted:

$$
\begin{aligned}
\rho_{o, i(p, T)}= & A_{0}+A_{1} p_{i} T_{i}+A_{2} p_{i}+A_{3} p_{i}^{2}+A_{4} T_{i} \\
& +A_{5} T_{i}^{2}
\end{aligned}
$$

where $\rho_{o, i(p, T)}$ is the oil phase density of each section, $\mathrm{kg} / \mathrm{m}^{3}$; $p_{i}, T_{i}$ is the oil phase pressure and temperature of each section, $\mathrm{Pa},{ }^{\circ} \mathrm{C}$.

Through the above formula, density change of the oil phase can be obtained, as shown in Figure 2.

2.2.4. Determination of Kill Fluid Density. In general, kill fluid is a mixture of liquid water or oil. Accordingly, this paper calculates the density of kill fluid by considering the liquid water and liquid oil volume ratio coefficient. In the liquid phase, aqueous phase volume ratio coefficient is $\lambda_{1}$ and oil phase volume ratio is $\left(1-\lambda_{1}\right)$, so the liquid density $\rho_{f}(p, T)$ calculation equation is shown:

$$
\rho_{f}(p, T)=\lambda_{1} \rho_{w}(p, T)+\left(1-\lambda_{1}\right) \rho_{o}(p, T) .
$$

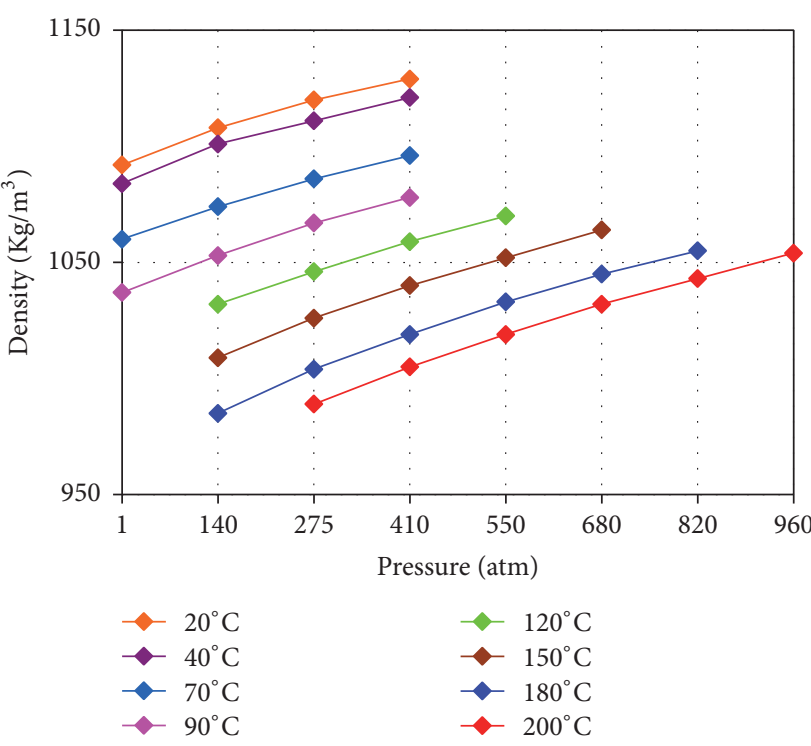

FIGURE 2: Density of oil phase under different temperatures and pressures.

The following equation can be obtained from (23):

$$
\begin{aligned}
& \rho(p, T) \\
& =\frac{\rho_{0}\left(p_{0}, T_{0}\right)}{1+\lambda\left(\rho_{f}\left(p_{0}, T_{0}\right) /\left(\lambda_{1} \rho_{w}(p, T)+\left(1-\lambda_{1}\right) \rho_{o}(p, T)\right)-1\right)} .
\end{aligned}
$$

\section{Case Study}

3.1. Analysis of Influence Factors in Model. Dynamic kill is a relatively new type of well kill method in deep water drilling. Here some wells' kill data are chosen for a case study. Some of the related parameters of this well are shown in Table 3.

During the initial "dynamic stable stage," the sea water could be chosen as the initial density of well kill fluid.

$$
\rho_{m 1}=1018 \mathrm{~kg} / \mathrm{m}^{3} \text {. }
$$

During "static stable stage," the temperature and pressure below the surface can be calculated on the condition that the surface temperature is $21^{\circ} \mathrm{C}$ and relative pressure is zero according to (8) and (9) where the temperature and pressure of the deep water are taken into account to cause the density of kill fluid change.

With (28), the density of well kill fluid can be calculated under a temperature and pressure. The composition of the selected well kill fluid is shown in Table 4 . The trend of the density $\rho_{m 2}$ of the well kill fluid at static stable stage is shown in Figure 3 with temperatures shown in below: $26.67^{\circ} \mathrm{C}$, $93.33^{\circ} \mathrm{C}$, and $176.67^{\circ} \mathrm{C}$. It can be seen that temperature rises as density decreases under the same pressure. At higher temperature levels, the density changes with pressure are insignificant. Comparison has been done to real values with the calculated values for error analysis shown in Figure 4. The error is larger at lower temperature levels and pressure conditions, while the error can be reduced as temperature 
TABle 3: Parameters of the well of case study.

\begin{tabular}{|c|c|c|c|c|c|}
\hline Water depth (m) & 549 & Known pressure of shallow gas (Mpa) & 13.3 & Surface temperature of sea water $\left({ }^{\circ} \mathrm{C}\right)$ & 21 \\
\hline Well depth (m) & 1036 & Length of DP (m) & 946 & Length of $\mathrm{D}(\mathrm{m})$ & 60 \\
\hline Length of conductor pipe $(\mathrm{m})$ & 104 & $\mathrm{OD}$ of $\mathrm{DP}(\mathrm{m})$ & 0.14 & OD of DC $(\mathrm{m})$ & 0.22 \\
\hline Conductor pipe OD (m) & 0.76 & ID of DP (m) & 0.12 & ID of DC (m) & 0.09 \\
\hline Conductor pipe ID (m) & 0.71 & Hole size $(\mathrm{m})$ & 0.31 & $\mathrm{PV}(\mathrm{pa} \cdot \mathrm{s})$ & 0.001 \\
\hline Length of riser $(\mathrm{m})$ & 570 & Normal drilling fluid density $\left(\mathrm{kg} / \mathrm{m}^{3}\right)$ & 1018 & & \\
\hline
\end{tabular}

TABLE 4: The sample composition of well kill fluid.

\begin{tabular}{lc}
\hline Each component content & \\
Diesel $\left(\mathrm{cm}^{3}\right)$ & 115.9 \\
Emulsifier $(\mathrm{g})$ & 6.8 \\
Humectant $(\mathrm{g})$ & 4.5 \\
Fluid loss control agent $(\mathrm{g})$ & 9.1 \\
Organic $(\mathrm{g})$ & 2.7 \\
Simulate cuttings $(\mathrm{g})$ & 9.1 \\
$\mathrm{CaCl}_{2}(\mathrm{~g})$ & 9.2 \\
Lime $(\mathrm{g})$ & 9.1 \\
Barite $(\mathrm{g})$ & 85.8 \\
Water $\left(\mathrm{cm}^{3}\right)$ & 20.0 \\
\hline Kill fluid density at surface $\left(\mathrm{kg} / \mathrm{m}^{3}\right)$ & 1320 \\
\hline
\end{tabular}

and pressure increase, indicating that the model is more applicable in the high temperature and high pressure conditions.

3.2. Model Application. Kill operation cannot be conducted above the seabed wellhead; therefore, only fluid density below is calculated in this sample. First of all, wellbore temperature field can be elicited according to the data in Figure 3; then, temperature field model can be obtained as shown in Figure 5 on (8).

As is shown in Figure 5, based on the boundary condition that bottom temperatures are equal, temperature distribution can be obtained. The lowest geothermal gradient exists at the seabed. In addition, annual temperature rises with the increasing of the depth. However, it decreases when approaching the bottom part, whereas the temperature in the drilling string continues to increase.

From (28) and (29), density distribution rule of the circulation can be elicited. And then result is compared with that in the in static condition.

As is shown in Figure 6, comparison indicates that temperature and pressure exert a greater influence on annual density and density variation in the drilling string. Compared with Fu's method [13], it is proven to be more accurate as shown in Figure 6. Density declines sharply when it moves towards the bottom of the well; however, density increase will be slow or even static in high temperature. Meanwhile, density in an annulus keeps increasing, indicating that bottom pressure plays a decisive role.

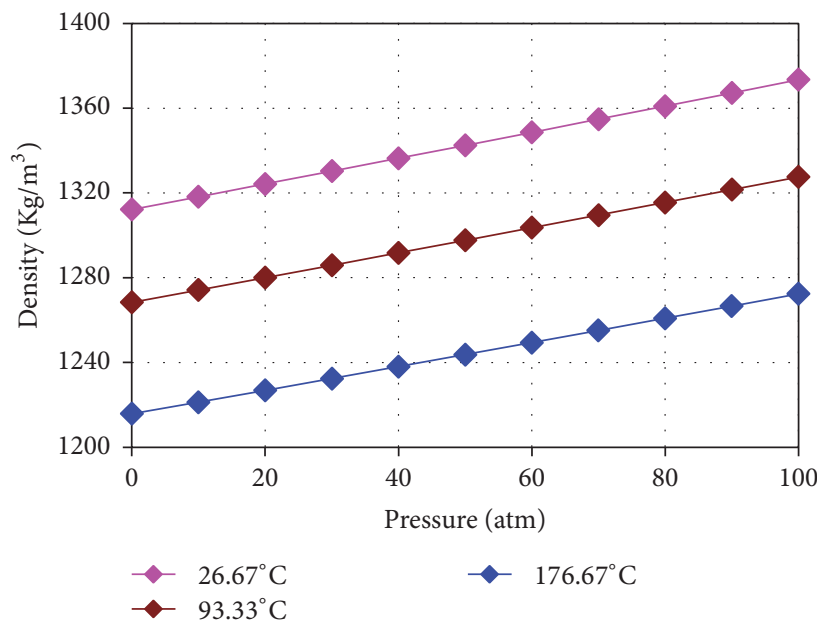

FIGURE 3: Calculated kill fluid density under different temperatures and pressures.

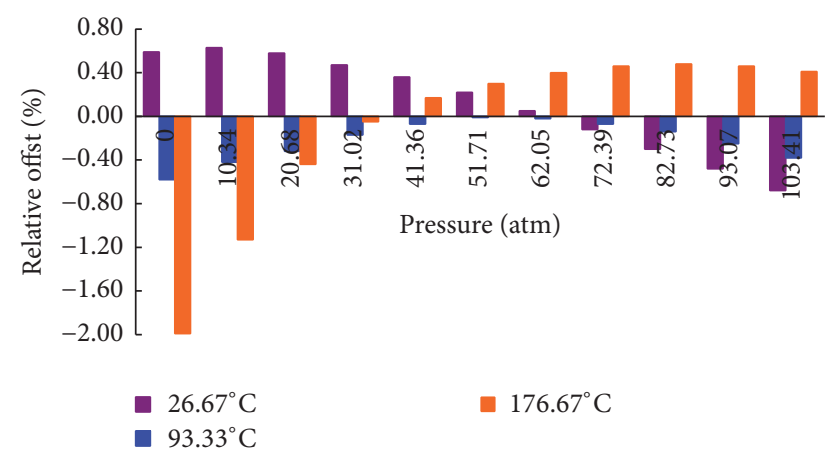

FIGURE 4: Error analysis of real value and calculated value.

\section{Conclusions}

(1) In this paper, all phases of the kill fluids in dynamic well kill operation are taken into account in which this paper further divides the process into dynamic stable stage and static stable stage. If the initial kill fluid and heavy kill fluid are mixed together, it will greatly increase the difficulty of calculation. The model developed in this paper is more accurate in predicting fluid density than previous models since it fully considers initial kill well and heavy kill fluid flowing in the wellbore with a grading (section) method.

(2) The kick tolerance decreases with the increase of water depth, which requires the accurate control of well kill fluid 


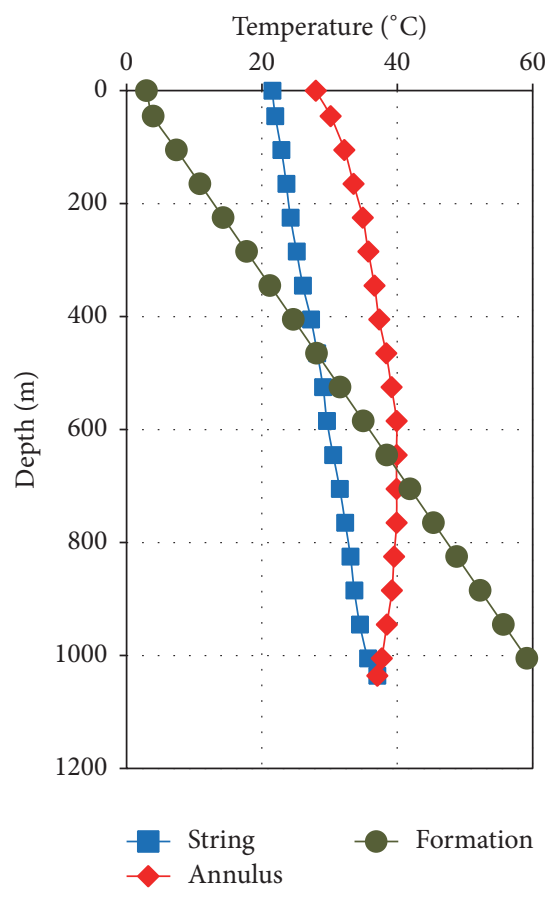

FIGURE 5: Temperature field of wellbore under mudline.

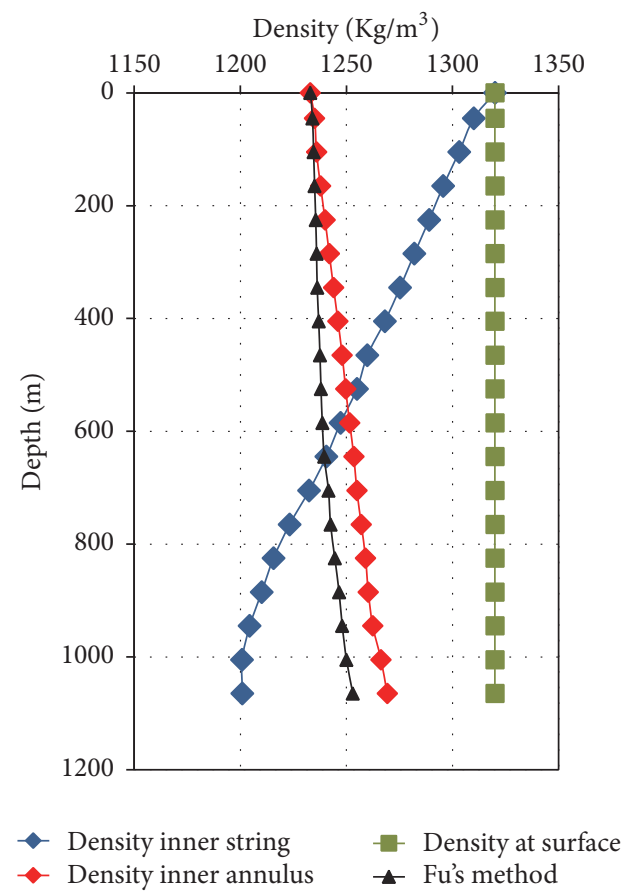

FIGURE 6: Kill fluid density distribution of wellbore under mudline.

density. Considering the characteristic of temperature and pressure in the deep water environment, kill fluid density is affected by the coupling of temperature and pressure.

(3) Well liquid density is inversely proportional to temperature, while it is proportional to pressure. The effect of pressure on density change is more significant at higher temperatures. Density of oil phase is inversely proportional to temperature and proportional to pressure, whereas the change is relatively insignificant.

(4) With the temperature increasing, the kill fluid in the string declines gradually whereas it keeps constant when reaching the bottom and temperature in the annulus increase as well under the seafloor. However, the influence of the kill timing variation on the density is not taken into consideration in this paper; therefore, further research on this subject will be conducted in the future.

\section{Competing Interests}

The authors declare that there is no conflict of interests regarding the publication of this paper.

\section{Acknowledgments}

The authors gratefully acknowledge financial support from "The National Natural Science Foundation of China" under the following projects: "The Stability Analysis of Wellhead and Study of Riser-Conductor (Casing) Characters in Deep Water" with Fund no. 51574261, "High Speed Flow in Production Pipe Column Induced Vibration Characteristics of High Pressure Gas Wells" with Fund no. 51274219, and "Basic Research on Drilling and Completion of Complex Oil and Gas" with Fund no. 51221003.

\section{References}

[1] J. Leblanc and R. Lewis, "A mathematical model of a gas kick," Journal of Petroleum Technology, vol. 20, no. 8, pp. 888-898, 1968.

[2] S. Ohara, Improved Method for Selecting Kick Tolerance During Deepwater Drilling Operation, Louisiana State University, Baton Rouge, La, USA, 1995.

[3] J. O. L. Nunes, "Mathematical model of a gas kick in deep water scenario," in Proceedings of the IADC/SPE Asia Pacific Drilling Technology, IADC/SPE 77253, Jakarta, Indonesia, 2002.

[4] X. F. Li, X. Q. Zhuang, and X. X. Sui, "Study on two-phase gas-liquid flow during gas kick," Journal of Engineering Thermophysics, vol. 25, no. 1, pp. 73-76, 2004.

[5] B. Sun, Z. Wang, P. Gong, and R. Song, "Application of a sevencomponent multiphase flow model to deepwater well control," Acta Petrolei Sinica, vol. 32, no. 6, pp. 1042-1049, 2011.

[6] Z. Fazhan, China New Technologies and Products, no. 8, 2011.

[7] T. G. Chen and Z. C. Guan, Drilling Engineering Theory and Technology, China University of Petroleum press, Beijing Shi, China, 2006.

[8] D. G. Robert, Blowout and Well Control Handbook, Gulf Professional, Oxford, UK, 2003.

[9] X. L. Jiang, Z. M. Lei, and Q. B. Meng, "Evaluation of equivalent circulating density in deep water dynamic kill drilling," Applied Mechanics \& Materials, vol. 121-126, pp. 3048-3052, 2012.

[10] Y. Zhanhua, Z. Shihua, R. Qiujun et al., "Study on shallow gas well killing fluid safety value," Petroleum Geology and Engineering, vol. 27, no. 4, pp. 108-110, 2013.

[11] M. P. Ren, X. F. Li, and Q. T. Ma, "A new design method of killing fluid density against blowout during tripping," Petroleum Drilling Techniques, vol. 41, no. 1, 2013. 
[12] X. Peng, Study on Dynamic Kill Drilling in Deep Water, China University of Petroleum, Beijing Shi, China, 2008.

[13] J. Fu, J. Feng, P. Chen, H. Wei, and Z. Liu, "Simulation on wellbore pressure during dynamic kill drilling in deep water," Shiyou Xuebao/Acta Petrolei Sinica, vol. 36, no. 2, pp. 232-237, 2015.

[14] S. Levitus and T. Boyer, "World Ocean Atlas 1994, 4: Temperature. Wash., D. C," NOAA Atlas NESDIS 4, U.S. Government Printing Office, 117 pages, 1994.

[15] Z. Qiu and S. Q. Cai, "Distribution characteristics of mean sea temperature relative to thermocline in deep water of nansha islands sea area," Tropic Oceanology, vol. 19, no. 4, pp. 10-14, 2000.

[16] G. Wang, X.-L. Pu, X.-S. Luo, and Q.-L. Hou, "Density of waterbase drilling fluid at HTHP," Journal of Southwest Petroleum University, vol. 29, no. 5, pp. 97-99, 2007.

[17] L. L. Hoberock, D. C. Thomas, and H. V. Nickens, "Bottom hole mud pressure variations due to compressibility and thermal effects," in Proceedings of the IADC Drilling Technology Conference, Houston, Tex, USA, March 1982.

[18] M. D. Politte, "Invert oil mud rheology as a function of temperature and pressure," in Proceedings of the SPE/IADC Drilling Conference, Paper SPE/IADC 13458, New Orleans, La, USA, March 1985.

[19] Z. Haobo, F. Honghai, Z. Yinghu, W. E'Chuan, and P. Qi, "A comprehensive hydraulic calculation method of nonnewtonian fluids used four-parameter model," SOCAR Proceedings, vol. 2013, no. 2, pp. 39-45, 2013. 


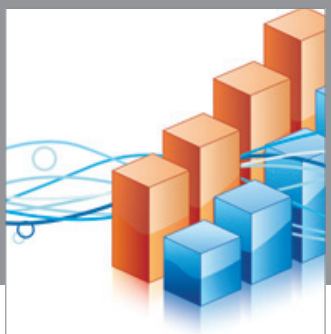

Advances in

Operations Research

vatem alat4

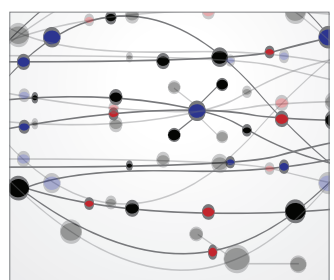

\section{The Scientific} World Journal
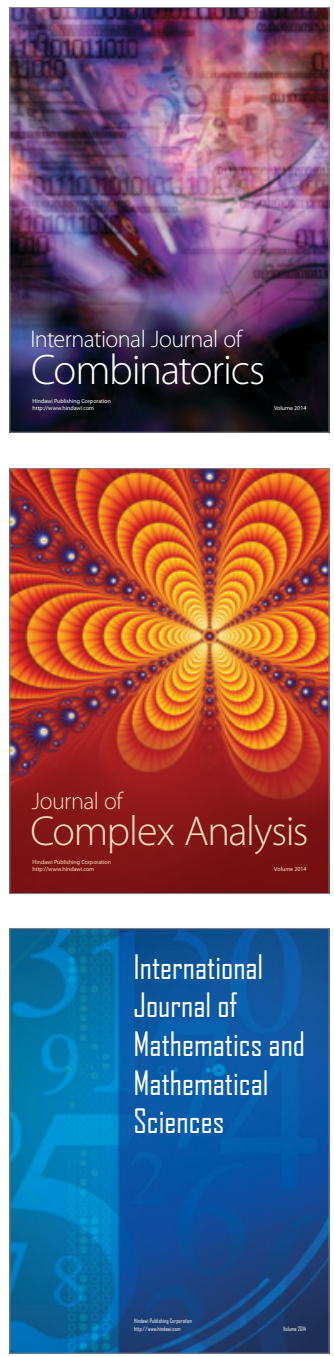
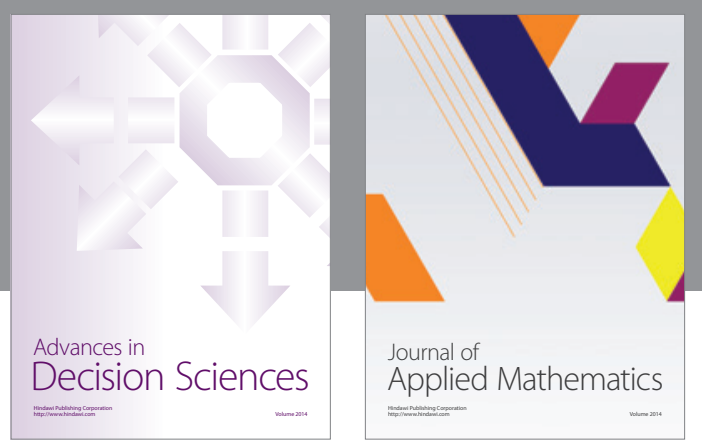

Algebra

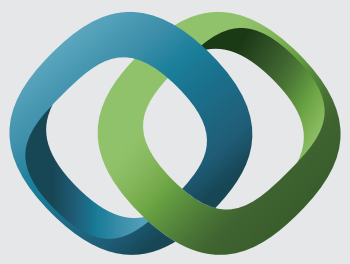

\section{Hindawi}

Submit your manuscripts at

https://www.hindawi.com
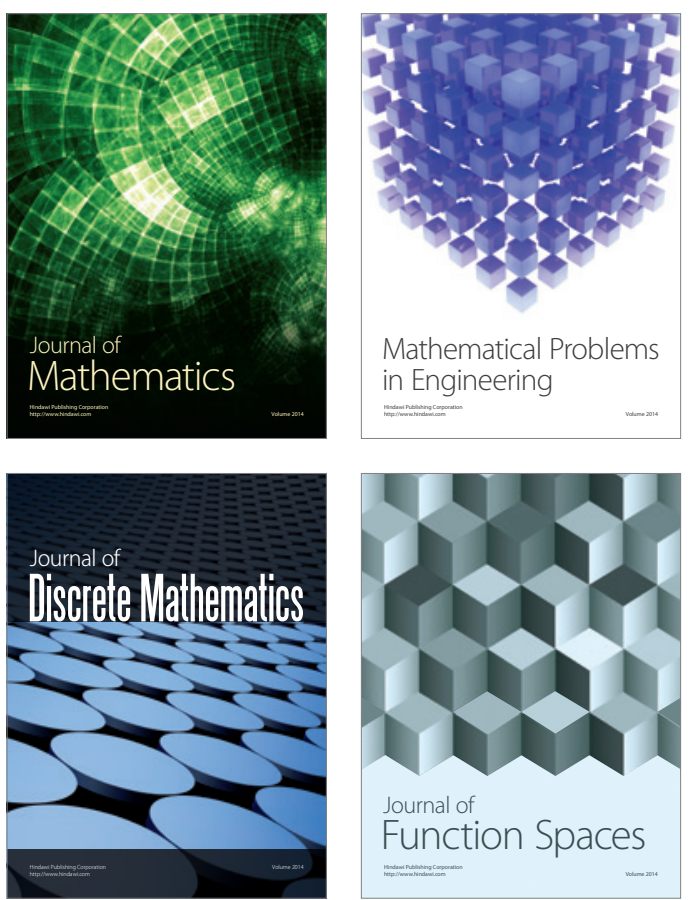

Mathematical Problems in Engineering
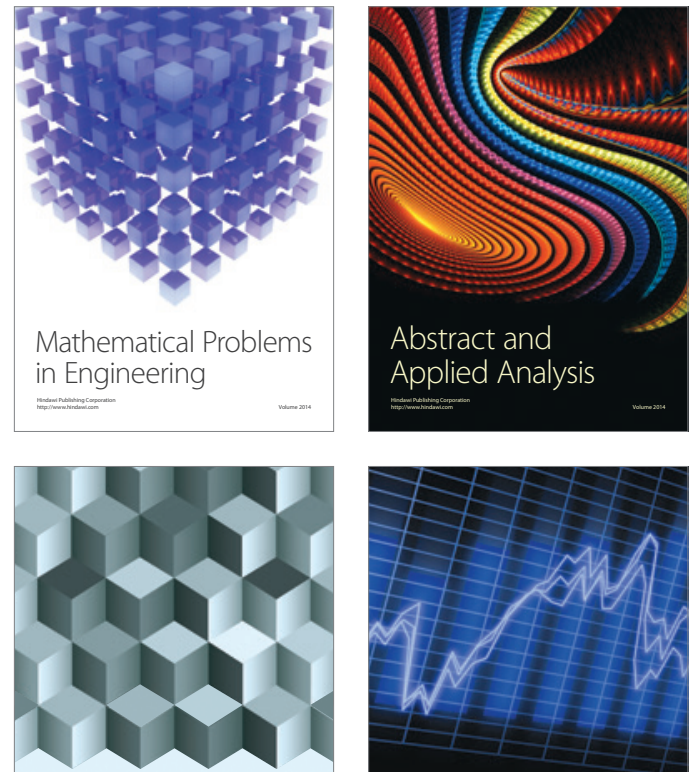

Journal of

Function Spaces

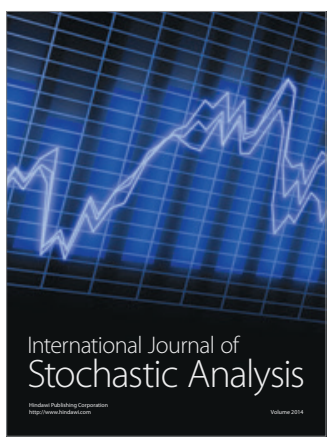

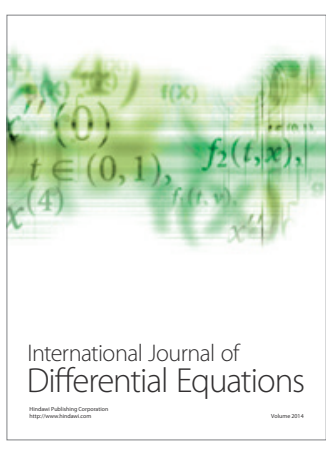
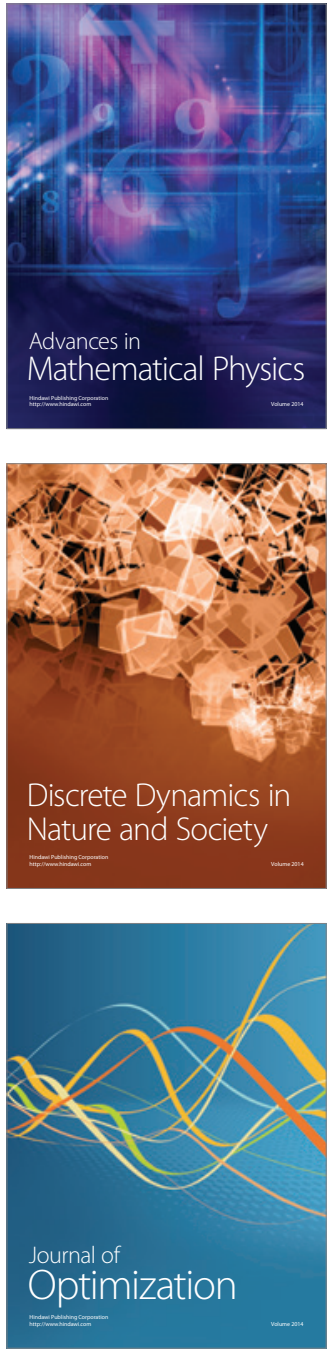